\title{
Hubungan Adversity Quotient Dengan Kecemasan Menghadapi Dunia Kerja Pada Freshgraduate Universitas Syiah Kuala
}

\author{
Correlation Adversity Quotientand the Anxiety in Facing the \\ Working World on Fresh graduate from Syiah Kuala University
}

\author{
T.M. Noor Rachmady ${ }^{1}$, Eka Dian Aprilia ${ }^{2}$ \\ Universitas Syiah Kuala, Fakultas Kedokteran, Program Studi Psikologi \\ e-mail: ${ }^{1}$ ampoen99@gmail.com, ${ }^{2}$ eka.aprilia@unsyiah.ac.id
}

KATA KUNCI : Adversity quotient, Kecemasan menghadapi dunia kerja, Fresh graduate

KEYWORDS : Adversity quotient, anxiety in facing the working world, Fresh graduate

ABSTRAK: Persaingan di dunia kerja pada era modern sekarang ini semakin sulit, fenomena tersebut berdampak pada pengangguran yang semakin meningkat setiap tahunnya. Hal tersebut menyebabkan kecemasan pada fresh graduate yang baru memasuki dunia kerja. Diketahui salah satu faktor yang dapat meminimalisirkan kecemasan pada fresh graduate adalah adversity quotient. Hal ini memungkinkan fresh graduate mampu mengatasi kesulitan terkait persaingan dunia kerja. Tujuan penelitian adalah untuk mengetahui hubungan antara adversity quotient dengan kecemasan menghadapi dunia kerja pada fresh graduate Universitas Syiah Kuala. Teknik pengambilan sampel yang digunakan adalah incidental sampling. Sampel penelitian berjumlah 257 fresh graduate (120 laki-laki dan 137 perempuan). Pengumpulan data menggunakan skala Adversity quotient yang disusun oleh Khairiyah (2016) dan skala kecemasan menghadapi dunia kerja yang disusun oleh Nugroho (2010). Analisis data menggunakan teknik korelasi Pearson yang menunjukkan nilai koefisien korelasi $(\mathrm{r})=-0,598(\mathrm{p}<0,05)$ sehingga dapat diartikan bahwa terdapat hubungan negatif dan signifikan antara adversity quotient dengan kecemasan menghadapi dunia kerja pada fresh graduate Universitas Syiah Kuala dan hipotesis dalam penelitian ini diterima.

ABSTRACTCompetition in the world of work in the modern era is now more difficult, the phenomenon has an impact on unemployment is increasing every year. This causes anxiety on fresh graduate who just entered the world of work. Known one of the factors that can minimize anxiety in fresh graduate is adversity quotient. This allows fresh graduate to overcome difficulties related to the competition of the work world. The purpose of this research is to find out the relationship between adversity quotients with anxiety to face work world at fresh graduate of Syiah Kuala University. The sampling technique used is incidental sampling. The sample of the study amounted to 257 fresh graduates (120 men and 137 women). Data collection using the Adversity quotient scale compiled by Khairiyah (2016) and the scale of anxiety against the world of work compiled by Nugroho (2010). Data analysis using Pearson correlation technique showed correlation coefficient $(r)=-0,598(p<0,05)$ so it can be interpreted that there is negative and significant relationship between adversity quotient with anxiety to face work world at fresh graduate of Syiah Kuala University and the hypothesis in this research is accepted. 


\section{PENDAHULUAN}

Pendidikan tinggi dan menjadi sarjana bagi masyarakat merupakan kebutuhan di era globalisasi yang terus berkembang untuk kehidupan yang lebih baik (Rosliani dan Ariati, 2016). Atmanti (2005) menyebutkan pendidikan yang semakin tinggi bermanfaat untuk memperluas pengetahuan, meningkatkan pemahaman teknis modern dan kepemimpinan serta perangsang untuk menciptakan pembaharuan-pembaharuan dalam kehidupan masyarakat. Lulusan perguruan tinggi umumnya berusia 23 sampai dengan 25 tahun yang tergolong ke dalam kelompok usia dewasal awal (Hurlock, 2009).

Masa dewasa awal ditunjukkan oleh dua kriteria, yaitu kemandirian ekonomi dan kemandirian dalam membuat keputusan (Santrock,2009). Perkembangan karir pada usia dewasa awal menjadi fokus utama dan memiliki pekerjaan tetap serta penghasilan menjadi tanda seseorang memasuki tahapan masa dewasa. Proses pencarian pekerjaan adalah tuntutan social yang harus dihadapi kelompok dewasa awal termasuk sarjana baru.Namun demikian, mencari pekerjaan di Indonesia bukan hal yang mudah. Terjadi persaingan yang begitu ketat di antara sesama pencari kerja sehingga membuat individu berusaha untuk terus meningkatkan kualitas diri terutama kualitas pendidikan yang dimiliki (Lestari dan Budiharto, 2006). Banyaknya orang yang ingin mendapatkan pekerjaan dan terbatasnya lapangan kerja, menyebabkan ketimpangan dalam penyerapan pencari kerja yang berdampak pada meningkatnya pengangguran dalam suatu negara (Yunita, 2013). Tingginya angka pengangguran pada tingkat lulusan universitas dapat menimbulkan kegelisahan pada lulusan baru universitas (fresh graduate) tentang kemungkinan mereka mendapatkan pekerjaan.

Universitas Syiah Kuala (Unsyiah) merupakan salah satu universitas yang berada di Indonesia yang terletak di
Provinsi Aceh, merupakan perguruan tinggi negeri tertua dan salah satu perguruan tinggi yang memiliki nama besar di Aceh. Saat ini, Unsyiah memiliki lebih dari 50.000 orang mahasiswa yang menuntut ilmu di 12 Fakultas dan Program Pasca Sarjana. Setiap tahunnya, Unsyiah menghasilkan lulusan lebih dari 4000 orang. Unsyiah secara institusi telah resmi memperoleh nilai akreditasi " $A$ " dari Badan Akreditasi Nasional Perguruan Tinggi (BAN-PT) pada tahun 2015. Hal ini menjelaskan bahwa Unsyiah mengutamakan mutu, juga mengintegrasikan nilai-nilai universal, nasional, lokal untuk melahirkan sumber daya manusia yang memiliki keselarasan dalam antara IPTEK, IMTAQ dan meningkatkan kualitas akademik untuk menghasilkan lulusan yang berdaya saing tinggi (Universitas Syiah Kuala, 2016).

Lulusan Unsyiah seharusnya lebih mudah mendapatkan pekerjaan dibandingkan lulusan universitas lain yang ada di Aceh. Adhayaksa dan Rusgiyono (2010) menyebutkan bahwa salah satu kriteria yang sangat diperhitungkan dalam seleksi penerimaan kerja adalah nama besar perguruan tinggi. Akan tetapi, faktanya masih banyak lulusan Unsyiah yang belum bekerja. Hal ini didasarkan pada survey yang dilakukan oleh CDC (Career Development Center) Unsyiah pada lulusan Universitas Syiah Kuala yang menyatakan bahwa setelah 2 tahun masih ada sebesar $24,7 \%$ alumni yang belum mendapatkan pekerjaan. CDC (Career Development Center) Unsyiah menyebutkan bahwa ada beberapa alasan yang menyebabkan fresh graduate sulit untuk mendapatkan pekerjaan, diantaranya kesesuaian dengan bidang keilmuan yang dikuasai, gaji, tidak ada pilihan pekerjaan lain, kedekatan dengan tempat tinggal, dan lainnya.

Dunia kerja merupakan suatu hal yang akan menjadi pengalaman baru bagi individu dan setiap individu memiliki gambaran yang berbeda mengenai dunia kerja. Sebagian beranggapan bahwa dunia kerja merupakan suatu hal yang 
menyenangkan, tapi sebagian juga beranggapan bahwa persaingan dalam dunia kerja adalah suatu hal yang menakutkan sehingga menimbulkan rasa tertekan. Rasa tertekan yang dialami individu berupa perasaan takut. Perasaan takut yang dialami oleh seseorang tentang sesuatu yang akan terjadi berupa ancaman-ancaman dan kesulitan yang sebenarnya belum jelas dan tidak realistis yang akan muncul di masa depan sehingga dapat membahayakan kesejahteraan seseorang dikenal dengan istilah kecemasan (Alloy, Riskind \& Manos, 2005).

Kecemasan yang paling dikhawatirkan saat mencari pekerjaan pada fresh graduate yaitu psikotes dan interview (Isnaini \& Lestari, 2015). Menurut Astuti (dalam Isnaini \& Lestari, 2015) kegagalan saat mengikuti wawancara (interview) disebabkan oleh irrational believe yang dapat memengaruhi kognitif, perasaan, dan perilaku. Berdasarkan beberapa lowongan kerja di berbagai media, peneliti berpendapat bahwa kecemasan juga dapat timbul disebabkan salah satu kualifikasi kerja yaitu penyedia kerja meminta pengalaman kerja, sedangkan fresh graduate merupakan lulusan yang baru lulus dan belum pernah memiliki pengalaman pekerjaan sebelumnya.

Kecemasan yang tidak teratasi dengan baik pada fresh graduate dapat menimbulkan dampak negatif bagi individu, salah satunya gangguan perilaku berupa perilaku menghindar. Perilaku menghindar dapat menghambat individu untuk mendapat pekerjaan (Mu'arifah, 2005). Kecemasan yang tidak tertangani dengan baik pada fresh graduate juga akan membuat individu menjadi depresi, tidak memiliki rasa percaya diri, merasa diri selalu gagal, sering melamun atau merenung, mudah putus asa, dan dapat mengalami kecemasan kronis (Isnaini \& Lestari, 2015).

Fresh graduate diharapkan mampu mengatasi rasa cemasnya, sehingga mereka dapat fokus dalam mendapatkan pekerjaan daripada harus secara terus-menerus memikirkan kesulitan dalam mendapatkan pekerjaan tersebut.Kemampuan seseorang dalam mengatasi kesulitan hidup dan mengukur kemampuannya dikenal dengan konsep adversity quotient (Stoltz, 2000). Stoltz (2000) menjelaskan bahwa individu yang memiliki adversity quotientyang tinggi adalah individu yang memiliki kegigihan dalam hidup dan tidak mudah menyerah, memiliki kekebalan atas ketidakmampuan dirinya menghadapi masalah dan tidak akan mudah terjebak dalam kondisi keputusasaan. Adversity quotient tinggi menunjukkan kemampuan untuk bertahan dan terus berjuang ketika dihadapkan pada sebuah permasalahan hidup, penuh motivasi, dorongan, ambisi, antusiasme, dan semangat yang tinggi.

Berdasarkan penjelasan di atas dan minimnya penelitian yang meneliti mengenai hubungan antara adversity quotientdan kecemasan menghadapi dunia kerja pada fresh graduate Universitas Syiah Kuala, maka peneliti tertarik untuk meneliti mengenai hubungan adversity quotientdengan kecemasan menghadapi dunia kerja pada fresh graduate Universitas Syiah Kuala.

\section{METODE PENELITIAN}

Penelitian ini menggunakan pendekatan kuantitatif dengan jenis penelitian korelasi. Sampel dalam penelitian ini adalah 257 yang merupakan freshgraduate Universitas Syiah Kuala yang diperoleh denganmenggunakan metode nonprobabilitysampling dengan teknik incidental sampling. Data dikumpulkan dengan dua buah skala psikologi adaptasi yaitu, adversity quotient yang disusun oleh Khairiyah (2016) dengan koefisien releabilitas 0,801 dan Kecemasan menghadapi dunia kerja yang disusun oleh Nugroho dengan koefisien reliabilitas 0,927 (2010). Metode analisis data menggunakan teknik parametrik yaitu correlation Pearson (Priyatno, 2011).

\section{ANALISIS DAN HASIL}


Hasil analisis uji statistik korelasi menunjukkan hasil koefisien korelasi sebesar $(r)=-0,598(p<0,05)$. Hasil tersebut menunjukkan bahwa terdapat hubungan yang negatif dan signifikan antara adversity quotient dengan kecemasan menghadapi dunia kerja. Dengan demikian, hipotesis yang diajukan diterima yaitu terdapat hubungan antara adversity quotientdengan kecemasan menghadapi dunia kerja. Hasil analisis dengan menggunakan korelasi Person ProductMoment menunjukkan nilai koefisien determinasi $\left(\mathrm{r}^{2}\right)=0,358$ yang artinya terdapat 35,8\% sumbangan efektif adversity quotient terhadap kecemasan menghadapi dunia kerja, sementara $64,2 \%$ dari kecemasan menghadapi dunia kerja dipengaruhi oleh faktor-faktor lain.

Penelitian ini juga meneliti beberapa faktor yang dapat mempengaruhi kecemasan menghadapi dunia kerja di antaranya pengalaman organisasi, dimana freshgraduate yang di masa kuliahnya mengikuti organisasi sebanyak $62,6 \%$, kemudian $66,9 \%$ fresh graduate memiliki IPK berkisar 3,01-3,50 dengan predikat sangat memuaskan, dilanjutkan dengan freshgraduate melamar pekerjaan 1-10 kali dalam kurun 1 tahun sebanyak $81 \%$. Puspitasari (2013) mengatakan individu yang memiliki Adversity quotient yang tinggi akan mampu mengatasi kecemasan dan mampu mengerjakan sesuatu dengan baik. Berdasarkan penelitian ini kecemasan menghadapi dunia kerja pada fresh graduate $65,7 \%$ memiliki kecemasan dalam kategori sedang dan $70,8 \%$ fresh graduate memiliki adversity quotient dalam kategori sedang.

\section{DISKUSI}

Hasil penelitian ini dapat membuktikan bahwa terdapat hubungan yang negatif dan signifikan antara adversity quotientdengan kecemasan menghadapi dunia kerja. Puspitasari (2013) menjelaskan tingkat adversity quotient tinggi yang dimiliki oleh individu akan menyebabkan individu mampu bertahan mengatasi kecemasan sehingga mereka yang memiliki tingkat adversity quotient yang tinggi akan lebih terdorong untuk dapat mengerjakan sesuatu dengan baik. Individu yang mempunyai adversity quotient yang tinggi akan cenderung mempunyai sikap optimis, motivasi yang tinggi, ulet, dan tekun. Sehingga dengan begitu individu akan mampu menyelesaikan suatu kesulitan dengan baik atau mampu keluar dari hambatan tersebut. Beberapa aspek inilah yang mampu untuk meminimalisir kecemasan individu.

Pada variabel kecemasan menghadapi dunia kerja, fresh graduate pada penelitian ini memiliki kecemasan yang sedang (65,7\%). Greenberger dan Padesky (1995) menjelaskan bahwa perilaku seseorang yang mengalami kecemasan akan menghindari dan meninggalkan situasi permasalahan yang dialami, dan suasana hati yang cepat berubah. Dalam hal ini,fresh graduate tidak ingin membahas tentang dunia kerja. Berdasarkan fakta, fresh graduate yang mengalami kecemasan akan menghindari pembicaraan tentang dunia kerja dan juga dapat tersinggung dan mudah marah.

Penelitian ini juga menunjukkan bahwa 70,8\% fresh graduate Universitas Syiah Kuala memiliki adversity quotient yang sedang. Hal tersebut berarti tingkat adversity quotient pada fresh graduate Universitas Syiah Kuala secara umum tergolong sedang, dan berada pada kategori campers. Campers adalah golongan yang merasa cukup dengan apa yang sudah dicapai dan mengabaikan kemungkinan untuk melihat atau mengalami apa yang masih mungkin terjadi, masih menunjukkan usaha, dan masih mengerjakan apa yang perlu dikerjakan (Stoltz, 2000).

Subjek dalam penelitian ini mayoritas memiliki pengalaman organisasi $(52,6 \%)$. Pengalaman berorganisasi memiliki pengaruh terhadap adversity quotient. Menurut Dwika, Zulharman, dan Hamidy (2014) salah satu faktor yang memengaruhi 
adversity quotient adalah pengalaman berorganisasi. Pengalaman organisasi akan membantu meningkatkan adversity quotientindividu, karena individu yang memiliki pengalaman berorganisasi akan lebih banyak menemui kesulitan dikarenakan selain harus menghadapi kesulitan akademis, individu juga harus menghadapi kesulitan di organisasi sehingga individu akan lebih meningkatkan daya juangnya dibandingkan individu yang tidak memiliki pengalaman berorganisasi. Selain itu individu yang memiliki pengalaman berorganisasi juga akan lebih berani mengambil keputusan, berkomunikasi di depan umum, dan memiliki jiwa kepemimpinan.

Novanto dan Yulianti (2015) menjelaskan bahwa IPK merupakan cerminan utama pencapaian prestasi akademik selama mahasiswa menempuh studi di perguruan tinggi. Pada penelitian ini ditemukan bahwa mayoritas IPK fresh graduate termasuk dalam kategori yang memuaskan yaitu 66,9\%, hal ini dapat menjadi salah satu indikator penting yang mempengaruhi kecemasan dalam menghadapi dunia. IPK yang menjadi salah satu indikator prestasi akademik diprediksi akan dapat meminimalisir kecemasan yang dirasakan oleh individu (Basri, 2014).

Pada proses pelaksanaan penelitian, peneliti menyadari banyaknya kekurangan dalam penelitian ini. Beberapa kekurangan ini dapat dijadikan pertimbangan untuk penelitian selanjutnya. Pertama, banyaknya subjek penelitian yang sudah berada di luar kota Banda Aceh. Kedua, banyak subjek yang menolak untuk mengisi skala yang diberikan oleh peneliti pada saat pelaksanaan jobfair. Ketiga, alat ukur dianggap memiliki jumlah pernyataan yang cukup banyak sehingga subjek merasa jenuh untuk mengisi. Beberapa keterbatasan ini dapat dijadikan pertimbangan untuk penelitian selanjutnya.

\section{SIMPULAN}

Penelitian ini bertujuan untuk mengetahui hubungan antara adversity quotient dengan kecemasan menghadapi dunia kerja pada fresh graduate Universitas Syiah Kuala. Hasil penelitian ini menunjukkan ada hubungan negatif dan signifikan antara adversity quotient dengan kecemasan menghadapi dunia kerja pada fresh graduate Universitas Syiah Kuala. Hal tersebut mengindikasikan bahwa semakin tinggi adversity quotient maka semakin rendah kecemasan menghadapi dunia kerja. Hal ini terjadi karena adversity quotient yang dimiliki oleh fresh graduate akan memengaruhi kecemasan menghadapi dunia kerja pada fresh graduate tersebut. Selanjutnya, hasil penelitian ini menunjukkan bahwa umumnya fresh graduate Universitas Syiah Kuala berada pada kategori sedang atau campers untuk adversity quotient dan pada kategori sedang untuk kecemasan menghadapi dunia kerja.

\section{SARAN}

Berdasarkan hasil penelitian ini maka terdapat beberapa saran yang peneliti ingin sampaikan Kepada subjek penelitian yaitu fresh graduate agar dapat meningkatkan adversity quotient yang dimiliki dengan berusaha secara maksimal untuk menyelesaikan permasalahan mereka sendiri sebelum meminta bantuan kepada orang lain. Hal tersebut berkaitan dengan kecemasan yang muncul dalam menghadapi dunia kerja. Adversity quotientyang baik akan mempermudah fresh graduate untuk menghadapi dunia kerja.

Selanjutnya kepada Universitas Syiah Kuala kepada CDC (career developmental center) selaku civitas akademika Universitas Syiah yang bertugas untuk mendekatkan alumni dengan dunia kerja diharapkan agar lebih banyak mengadakan seminar, workshop, training, serta menghimbau kepada mahasiswa untuk mengikuti organisasi yang terdapat di universitas dengan maksud mengasah kemampuan diri individu. Hal ini dapat menjadi kesiapan untuk menghadapi dunia 
kerja sehingga adversity quotient menjadi lebih meningkat dan dapat mengurangi kecemasan mengahadapi dunia kerja pada fresh graduate.

Kepada Peneliti selanjutnya yang ingin meneliti dengan variabel yang sama, dianjurkan untuk lebih memperhatikan variabel lain yang mungkin memengaruhi adversity quotientdan kecemasan menghadapi dunia kerja seperti adversity emotional, kepercayaan diri, hardiness, prestasi akademik dan pengalaman berorganisasi. Selain itu dianjurkan untuk dapat melakukan penelitian secara langsung sehingga bisa mengawasi subjek penelitian sampai dengan selesai mengisi skala agar hasil penelitian lebih akurat dan tepat.

\section{DAFTAR PUSTAKA}

Adhayaksa, M. A., \& Rusgiyono, A. (2010). Persepsi dunia kerja terhadap lulusan fresh graduate S1 menggunakan multidimensional unfolding. 1(3). 49-57.

Alloy, L. B., Riskind, J. H., \& Manos, M. J. (2005). Abnormal psychology: current perspective (9th ed). New York: Mc. Graw Hill.

Atmanti. H. D. (2005). Investasi sumber daya manusia melalui pendidikan. Dinamika Pembangunan. 2(1). 30-39.

Basri, S. H. (2014). Kecemasan Mahasiswa Fakultas Dakwah dan Komunikasi Dalam Menghadapi Dunia Kerja. Jurnal PMI. 1(12). 121-140

Dwika, D. Y., Zulharman., \& Hamidy. (2014). Hubungan Pengalaman Berorganisasi Dengan Tingkat Adersity Quotient (AQ) Pada Mahasiswa Angkatan 2012 Fakultas Kedokteran Universitas Riau. JOM FK. $1(2)$.

Greenberger, D., \& Padesky, C, A. (1995). Mind Over Mood. New York: KP Company.

Hurlock, E. B. (2009). Psikologi Perkembangan: Suatu Perkembangan Sepanjang Rentang Kehidupan. Jakarta: Erlangga

Isnaini, N. S. N., \& Lestari, R. (2015). Kecemasan pada pengangguran terdidik Universitas. Jurnal Indigenous. 1(13), $39-50$.
Khairiyah, Y. (2016). Hubungan optimism menghadapi persaingan dunia kerja dengan adversity quotient pada mahasiswa universitas syiah kuala. Skripsi.

Lestari, W. A. \& Budiharto, S. (2006). Hubungan antara kepercayaan diri dengan kecemasan menghadapi dunia kerja pada mahasiswa psikologi universitas islam indonesia. Naskah Publikasi. Yogyakarta: Universitas Islam Indonesia.

Mu'arif, A. (2005). Hubungan kecemasan dengan agresifitas. Humanitas Indonesia Pscychological journal. 2(2), 102-111

Novanto, Y., \& Yulianti, L. (2015). Faktorfaktor yang berkaitan dengan prestasi akademik mahasiswa sekolah tinggi teologi" x". Tanjung Balai: Sekolah Tinggi Teologia Marturia.

Nugroho, T. A. F. (2010). Hubungan antara kepercayaan diri dengan kecemasan menghadapi dunia kerja pada mahasiswa semester akhir di fakultas psikologi universitas sanata dharma Yogyakarta. Skripsi. Yogyakarta: Universitas Sanata Dharma. Diakses pada tanggal 20 September 2016 melalui library.usd.ac.id.

Priyatno, D. (2011). Buku saku spss; Analisis statistik data, lebih cepat, efisien, dan akurat. Yogyakarta: PT Buku Seru.

Puspitasari, T. R. (2013). Adversity quotient dengan kecemasan mengerjakan skripsi pada mahasiswa. Jurnal Online Psikologi. 1 (2). 299-310.

Rosliani, N \& Ariati, J. (2016). Hubungan antara regulasi diri dengan kecemasan menghadapi dunia kerja pada pengurus ikatan lembaga mahasiswa psikologi Indonesia (ILMPI). Jurnal Empati. 5(4), 744-749

Santrock, J. W. (2009). Remaja (Ed. 11). Terjemahan: Benedictine Widyasinta. Jakarta: Erlangga.

Stoltz, PG. (2000). Adversity quotient: mengubah hambatan menjadi peluang (Terjemahan: T. Hermaya). Jakarta: Grasindo.

Universitas Syiah Kuala. (2014). Sejarah. Diakses pada tanggal 28 Januari 2017, dari http://www.unsyiah.ac.id/

Universitas Syiah Kuala. (2016). Data Lulusan. Diakses pada tanggal 25 Januari 2017, dari http://www.unsyiah.ac.id/ 
Yunita, E. (2013). Hubungan antara kepercayaan diri dengan kecemasan menghadapi dunia kerja pada mahasiswa semester akhir universitas muhammadiyah Surakarta. Naskah
Publikasi. Surakarta: Universitas Muhammadiyah Surakarta. Diakses pada tanggal 25 Agustus 2016 melalui http://eprints.ums.ac.id/28985/14/naskah _publikasi.pdf 